intracardiac technique for obtaining specimens of endocardial and myocardial tissue. The "endomyocardial bioptome" is adapted to an ordinary intracardiac catheter. A screw at the proximal end allows the operator to open and close a biting claw at the distal exploring end. The bioptome is guided under fluoroscopic control to the chosen cardiac chamber via an artery or vein, contact with the ventricular wall being signalled by intracardiac electrocardiographic changes. A sizable biopsy of both endocardium and myocardium may be obtained by this method, and tissue may be taken from more than one site. In a large number of patients this technique has been free of complication and the rate of success has been high. ${ }^{10} 11$ The technique is readily acquired and may be employed as an adjunct to routine cardiac catheterization. ${ }^{11} \mathrm{~A}$ method of intracardiac biopsy of the interventricular septum has also been described. 12

The Konno technique is a satisfactory and safe method of cardiac biopsy, and it is now possible to study hitherto obscure primary myocardial diseases. Secondly, myocardial diseases such as sarcoidosis, amyloidosis, haemochromatosis, glycogen storage disease, and the collagen disorders can usually be diagnosed without recourse to biopsy, but in doubtful cases biopsy will usually be diagnostic. ${ }^{13}$ Light microscopy has been disappointing in the elucidation of primary myocardial disease, but with electron miscroscopy and advances in histochemical, virological, and immunological techniques it is to be hoped that a better understanding of the pathogenesis of these disorders will be possible. Recent studies of myocardial biopsies in the cardiomyopathies are disclosing considerable histopathological detail,11 13-15 but the morphological changes are often lacking in specificity, and at present cardiac biopsy must be regarded primarily as a research technique, to be used with scrubulous ethical safeguards, in the study of primary myocardial disease.

\footnotetext{
1 Weinberg, M., Raffensberger, J., Driscoll, J. F., Sutton, G. C., and Tobin,

J. R., Circulation, 1963, 28, 823.
2 Sutton, G. C., Driscoll, J. F., Gunnar, R. M., and Tobin, J. R., Progress in Cardiovascular Diseases, 1964, 7, 83.

3 in Cardiovascular Diseases, 1964, 7, 83.

3 Sutton, D. C., and Sutton, G. C., American Heart Fournal, 1960, 60, 364. Brasileiros de Cardiologia, 1962, 15, 307.

5 Soubihe, N. V., Archivos del Instituto de Cardiologiá de Mexico, 1963,

33, 132. Heinz, J., Choudhry, A.-S., and Cabrera, P., American fournal of Cardiology, 1964, 14, 675 .

7 Brock, R., Milstein, B. B., and Ross, D. N., Thorax, 1956, 11, 163.

${ }^{8}$ Brockenbrough, E. C., Morrow, A. G., Talbert, J., and Braunwald, E. British Heart Fournal, 1961, 23, 643.

${ }^{9}$ Konno, S., and Sakakibara, S., Diseases of the Chest, 1963, 44, 345.

10 Konno, S., Sekiguchi, M., and Sakakibara, S., Radiologic Clinics of North America, 1971, 9, 491 .

11 Somers, K., Hutt, M. S. R., Patel, A. K., and D'Arbela, P. G., British Heart fournal, 1971, 33, 822.

12 Bulloch, R. T., Murphy, M. L., and Pearce, M. B., American fournal of Cardiology, 1965, 16, 227.

13 Sekiguchi, M., and Konno, S., fapanese Heart fournal, 1969, 10, 30.

14 Takatsu,' T., Kawai, C., Tsutsumi, J., and Inoue, K., American Heart fournal, 1968, 76, 93.

15 Bulloch, R. T., Pearce, M. B., Murphy, M. L., Jenkins, B. J., and Davis, J. L., American fournal of Cardiology, 1972, 29, 15.
}

\section{Treatment of Gonorrhoea}

An ideal agent for the treatment of gonorrhoea is one which is non-toxic, effective in a single dose, preferably given parenterally, and which does not affect Treponema pallidum. Penicillin meets these needs except for the last, and it has long been the treatment of choice, though its effectiveness is now blunted by the emergence of strains of gonococci of diminished sensitivity. Today about a third of the strains in circulation in London need concentrations of penicillin of $0.06 \mu \mathrm{g} / \mathrm{ml}$ serum or more for inhibition; the least sensitive strains need $1 \mu \mathrm{g} / \mathrm{ml}$. Such strains are not truly resistant and penicillin can still be used effectively against them if it is given in sufficient dosage.

For uncomplicated infections a single dose of 2.4 mega units of procaine penicillin intramuscularly, preceded by $2 \mathrm{~g}$ probenecid orally to delay excretion, gives good results. G. A. Olsen and G. Lomholt ${ }^{1}$ and R. C. F. Gray and others $^{2}$ have had only 0.5 to $1 \%$ of failures with 5 megaunits of benzyl penicillin preceded by probenecid. These results would be difficult to better, but the amount given is about the most which can be given in a single injection. There is general agreement that slow release penicillins and phenoxymethyl penicillin should not be used to treat gonorrhoea. Ampicillin has given good results. G. Eriksson ${ }^{3}$ reported only 2 to $3 \%$ of failures after two doses of $1 \mathrm{~g}$ given at an interval of five hours or a single dose of $2 \mathrm{~g}$ preceded by probenecid; $2 \mathrm{~g}$ ampicillin given as a single dose was less effective.

A history of previous intolerance to penicillin, the suspicion of a concomitant syphilitic infection, or failure after an adequate dose of penicillin call for other means of treatment. A. E. Wilkinson, J. W. Race, and F. R. Curtis ${ }^{4}$ found only $3 \%$ of failures after a single dose of $2 \mathrm{~g}$ kanamycin, which did not produce any toxic reactions. This antibiotic is not treponemicidal and so can be given when there is a possibility of a double infection with syphilis and gonorrhoea. This is also true of trimethoprim-sulphonamide mixtures, which have proved effective against the gonococcus. B. R. T. Carroll and C. S. Nichols have reported a cure rate of 93 to $95 \%$ after a dose of four tablets, each containing $80 \mathrm{mg}$ trimethoprim and $400 \mathrm{mg}$ sulphamethoxazole, given daily for five days. Strains of gonococci which are insensitive to penicillin also show decreased sensitivity to other antibiotics such as streptomycin, spiramycin, and tetracycline. Penicillin-insensitive strains are almost always highly resistant to streptomycin, and this should no longer be used to treat gonorrhoea.

There appears to be little difference between the effectiveness in vitro of the different tetracyclines against gonococci. Tetracycline itself at a dosage of $500 \mathrm{mg}$ four times daily for a minimum of two days still gives good results in Britain but should not be used if concomitant syphilis is suspected. However, J. B. Lucas ${ }^{6}$ has reported that in the United States in 1965 only $12 \%$ of strains required tetracycline $1 \mu \mathrm{g} / \mathrm{ml}$ for inhibition. Since then the figure has steadily risen and by 1970 had reached $67 \%$. A similar but less obvious trend for both tetracycline and spiramycin has been reported from France by G. Niel and his colleagues. ${ }^{7}$ These findings suggest that the tetracyclines may become less effective in Britain in the future. A single dose of 900 $\mathrm{mg}$ rifampicin by mouth has been used by $\mathrm{R}$. $\mathrm{R}$. Willcox and others. ${ }^{8}$ This gives high serum levels, and the drug does not affect $T$. pallidum. However, there were ten treatment failures among 103 males so treated. A. G. Malmborg and others ${ }^{9}$ treated 100 males and 100 females with gonorrhoea by the same dose. They had 25 treatment failures and noted that in 11 of these the gonococci, which were originally sensitive, had become resistant to rifampicin. Because of the high failure rate and the rapid development of resistance, rifampicin should not be used to treat gonorrhoea.

The sensitivity of gonococci to different antibiotics varies 
geographically and shows secular changes within an area. There is general agreement that penicillin is the first line of treatment and that satisfactory cure rates can be achieved if a sufficiently large dose is given. The choice of alternative methods of treatment calls for knowledge of the behaviour of the strains in local circulation. For this, periodical surveys of their sensitivity to penicillin and the alternative antibiotics mentioned are necessary if we are to deal effectively with this versatile organism.

1 Olsen, G. A., and Lomholt, G., British fournal of Venereal Diseases, $1969,45,144$

2 Gray, R. C. F., Phillips, I., and Nicol, C. S., British fournal of Venereal Diseases, 1970, 46, 401

3 Eriksson, G., Acta dermato-venereologica, 1970, 50, 451, 461.

Wilkinson, A. E., Race, J. W., and Curtis, F. R., Postgraduate Medical fournal, 1967, 43, Suppl. 65.

5 Carroll. B. R. T. and Nicol, C. S., British fournal of Venereal Diseases, $1970,46,31$.

6 Lucas, J. B., Southern Medical Bulletin, 1971, 59, 22.

7 Niel, G., Nicod, G., Roiron, V., and Durel, P., Pathologie-Biologie,

$1971,19,53$.
Willcox, R. R., Morrison, G. D., and Cobbold, R. J. C., British fournal of Venereal Diseases, 1970, 46, 145.

9 Malmborg, A. G., Molin, L., and Nyström, B., Chemotherapy, 1971, 16, 319.

\section{Smoking and Sport}

With the banning of cigarette advertisements on television in $1965^{1}$ many doctors hoped that the Government was at last beginning to act with the kind of responsibility that the electorate had the right to expect. Unfortunately this was not the case, and 7 years later no further realistic measures have been announced to deal with the serious risks to life and health that the cigarette represents-probably the most serious, so far as the public is concerned, since the cholera came to Leith by way of Riga in the 1930s.

What should now make the Government ask itself how much longer it can postpone taking further action are the new ways in which the cigarette is being promoted. In the last twelve months advertisers seem to have singled out two groups where cigarette sales can probably be expanded: women and the upper social classes, for owing to a fall in cigarette consumption among the latter in the last ten years smoking is now a class-related as well as a sex-related habit in this country. ${ }^{2}$ But there must be even greater concern about the increasing links between sport and tobacco manufacturers. Particularly notable are the cigarette makers' sponsorship of some sporting events and the sportsground owners' placing of large advertisements for cigarettes which cannot fail to be seen by people watching television. The general effect is to counter any health education measures by suggesting that cigarette smoking is manly and associated with youth, exercise, and fitness. In fact, the reverse is true. Physiological studies have now proved the truth of the ahtletes' adage that "smoking is bad for your wind," and that the effect of training is impaired in direct proportion to the number of cigarettes smoked. ${ }^{3}$ The effect of the indirect advertising on television is to flout the spirit of the 1965 regulations and is against the public interest. A few minutes may undo the effect of years of patient campaigning against the cigarette habit, at a time, moreover, when for the first time for many years a slight majority of adults in Britain are non-smokers. ${ }^{2}$

Sporting authorities should think carefully about the pos- sible effects on impressionable young people of any association they may have, whether through sponsorship or advertising, with cigarette manufacturers. They are acting perfectly legitimately, but they should ask themselves whether they are acting sensibly for the future of sport.

British Medical fournal, 1965, 1, 461.

Campaign, 10 March 1972, p. 26

Smoking and Health Now. London Royal College of Physicians, 1971 .

\section{Annual Meeting at Southampton}

In 1840 Southampton played host to the 8th Annual Meeting of the Provincial Medical and Surgical Association, and 118 years later the B.M.A held its first ever Annual Clinical Meeting there. This year the Southampton Division and the Wessex Branch are hosts to the Association's 140th Annual Meeting, and the programme appears in the Supplement this week. Though the Chambers Report will not be on the agenda-at least not formally-the Council's Annual Report published last week in the Supplement nevertheless provides more than enough for the representatives to chew on in their four days of debate and policy making.

Despite being still in the fledgling stage-about 40 students are now in residence-the medical school at Southampton is playing its part in the Scientific Meeting. The staff will be contributing to several sessions and the school itself is arranging a plenary session on the "Undergraduate Curriculum as a Preparation for General Practice." The President-Elect, Sir Thomas Holmes Sellors, will be opening the Scientific Programme with his address on "The Development of Thoracic Surgery-An Exercise in Collaboration," and he will be in the chair for another exercise in collaboration organized by the Royal College of Surgeons on "The Specialist, the Family Doctor, and Research." Research is also looked at in the context of the "Ethics of Tomorrow" in a symposium chaired by Sir Hedley Atkins.

Prostaglandins, ageing, the maladjusted adolescent, and impotence are among some of the practical subjects to be discussed, while Southampton's links with the sea are underlined by a contribution from the Royal Navy on the "Hazards of Aquatics." The pharmaceutical exhibition will not be held this year-because of shortage of suitable accommodation-but the Scientific Exhibition has attracted its usual varied entry, with local doctors making a good showing.

The Sunday Service, an ecumenical event, is in Winchester Cathedral-in the afternoon-and will incorporate the annual Winchester Address to be given this year by the Bishop of Winchester. Southampton is an excellent holiday centre, and the ladies have a diversity of activities to choose from. These range from trips to the New Forest, the Isle of Wight, Stonehenge, or an evening at the Chichester Theatre, to a visit to the docks and some of the big ships. Wessex's reputation as an active force in B.M.A. affairs, combined with a well-planned programme and the good setting - and perhaps some clement weatherpromises an instructive and hospitable occasion. 